\title{
Acute HIV infection with rapid progression to AIDS
}

\begin{abstract}
Acute HIV infection is rarely recognized as the signs and symptoms are normally unspecific and can persist for days or weeks. The normal HIV course is characterized by a progressive loss of CD4+ cells, which normally leads to severe immunodeficiency after a variable time interval. The mean time from initial infection to development of clinical AIDS is approximately 8-10 years, but it is variable among individuals and depends on a complex interaction between virus and host. Here we describe an extraordinary case of a man who developed Pneumocisits jiroveci pneumonia within one month after sexual exposure to HIV-1, and then presented with 3 consecutive CD4 counts bellow 200 cells $/ \mathrm{mm}^{3}$ within 3 months, with no other opportunistic disease. Although antiretroviral therapy $(\mathrm{AZT}+3 \mathrm{TC}+\mathrm{ATZ} / \mathrm{r})$ was started, with full adherence of the patient, and genotyping indicating no primary antiretroviral resistance mutations, he required more than six months to have a CD4 restoration to levels above 200 cells $/ \mathrm{mm}^{3}$ and 10 months to HIV-RNA to become undetectable.
\end{abstract}

Keywords: HIV, acute infection, progression, AIDS.

[Braz J Infect Dis 2010;14(3):291-293]@Elsevier Editora Ltda.

\section{INTRODUCTION}

HIV infection is characterized by a progressive loss of CD4+ cells, which normally leads to severe immunodeficiency after a variable time interval. Following infection with HIV-1, the majority of individuals present with a clinical picture characterized by a mononucleosis-like syndrome, a transient drop in CD4+ cells, and a subsequent recovery of these initially reduced CD4+ T cell counts to near normal levels. ${ }^{1}$ The mean time from initial infection to development of clinical AIDS is approximately 8-10 years, ${ }^{2-5}$ but can vary among individuals and depends on the complex interaction between virus and host. The strongest predictor for the speed of HIV-1 disease progression is viral load set point, and infected subjects with high levels of viremia usually progress to AIDS faster than those with lower viral load. ${ }^{6,7}$

Opportunistic infections that occur within the first months after infection with HIV-1 are extremely rare, and are often misdiagnosed or missed. Patients and treating physicians can be misguided by a negative HIV-1 test within the preceding months. Here we describe a case of a homosexual man who developed Pneumocisits jiroveci pneumonia within one month of infection by HIV-1.
This case emphasizes that clinicians need to be aware of the possibility of opportunistic infections occurring during early HIV-1 infection.

\section{CASE REPORT}

A 28-year-old male patient presented on April 4,2005 , with fever of $38^{\circ} \mathrm{C}$, a rash on the upper limbs, which extended to the trunk and face after 2 days, night sweats, headache, myalgia and fatigue. After 7 days, the symptoms spontaneously disappeared. This episode was preceded by a single high-risk sexual exposure to a partner of unknown HIV serostatus, seven days before the onset of symptoms. Apart from this single risk exposure, the subject reported to be in a monogamous relationship with his HIV-1-negative male partner that had no other risk factors for HIV infection (tested HIV-1 negative in March 2005 and still negative at the latest measurement in September 2008). He was also tested negative for HIV-1 on January 17, 2005 (antibody and p24 antigen negative), when an HIV-1 test was performed in a context of an acute episode of diarrhea.

Two weeks after rash onset (on April 22, 2005), the patient was seen at the emergency room of a private hospital complaining of cough and fever. A chest X-Ray showed interstitial
Authors

Marcio de Oliveira Silva

Milena Bastos

Eduardo Martins Netto

Nancy Alves de Lima Gouvea $^{2}$

Alex Jose Leite Torres

Esper Kallas ${ }^{2}$

David I Watkins ${ }^{3}$

Marcus Altfeld ${ }^{4}$

Carlos Brites ${ }^{1}$

${ }^{1}$ Universidade Federal da Bahia, Brazil.

${ }^{2}$ Faculdade de Medicina de São Paulo, Brazil.

${ }^{3}$ Wisconsin National Primate Research, USA. ${ }^{4}$ Partners AIDS Research Center, Infectious Diseases Unit, Massachusetts

General Hospital, Boston, USA.

Submitted on: 08/14/2009 Approved on: 11/25/2009

Correspondence to: Marcio de Oliveira Silva Rua Jorge Simões, 156 Ed. San Juan, apt. 302, Bonfim

Salvador - Bahia - Brazil CEP: 40415-720

Phone: +55-71-91979086 E-mail: oliveiras_m@ yahoo.com.br

We declare no conflict of interest. 
infiltration and he was prescribed moxifloxacin $(400 \mathrm{mg} / \mathrm{d}$, PO). There was no improvement, and after 48 hours he returned to the hospital with persistent symptoms, malaise and shortness of breath. A chest computerized tomography scan revealed an interstitial infiltrate suggestive of $P$. jiroveci pneumonia. His arterial oxygen pressure was $70 \mathrm{mmHg}$, with an $\mathrm{O}_{2}$ saturation index of $96 \%$. He was hospitalized, and received prednisone $1 \mathrm{mg} / \mathrm{kg}$, and sulphametoxazole plus thrimethoprim (800/160 mg, qid, 21d). Acid fast baciloscopy (AFB) and blood pyogenic cultures were negative. Fever disappeared after 48 hours, and clinical symptoms resolved. A new HIV-1 serological test (EIA) performed on April 24, 2005, was positive for HIV (p24 Gag; p 41 Env) antibodies, which was confirmed by Western Blot (p17, p31, p51, p55, p66 = negative, p24 weakly positive, Gp41, Gp120, Gp160 positive).

A CD4+ T cell count performed on May 24, 2005, was 24 cells $/ \mathrm{mm}^{3}$, while the CD8+ T cell count was 251 cells $/ \mathrm{mm}^{3}$. HIV-1 viral load was quantified using NASBA (NucliSENS, BioMerieux) and was over 7,000,000 copies HIV-1 RNA per mL plasma. At a follow-up visit on June 08,2007 , the HIV-1 viral load had decreased to $3,200,000$ copies/mL and CD4+ and CD8+ T cell counts had increased to 61 and 799 cells $/ \mathrm{mm}^{3}$, respectively, without the initiation of any antiretroviral therapy. A genotyping test for potential antiretroviral drug resistance mutations performed on May 24, 2005, using the Trugene HIV-1 assay showed no evidence of drug-resistance mutations, mRNA flow cytometric analysis using ViroTect, Invirion Diagnostics Inc. ${ }^{8}$ revealed a dual-tropic virus infection. He was discharged from hospital on May 11,2005, without any symptoms.

He returned to hospital on June 11, 2005, with a clinical picture suggestive of upper respiratory tract infection (fever, headache, nasal congestion). An X-Ray of his face showed sinusitis, which was successfully treated with amoxacillinclavulanate $(500 / 125 \mathrm{mg}$, tid, $14 \mathrm{~d})$. His plasma viral load was 2,900,000 copies/mL; CD4+ cells count had increased to 136 cells $/ \mathrm{mm}^{3}$ (June 14, 2005). The patient was started on antiretroviral (ARV) therapy using AZT + 3TC + ATV/r on June 14, 2005, and then discharged. After 2 weeks of therapy (June 28, 2005), his viral load decreased to 11,000 copies/mL and CD4 count was 62 cells $/ \mathrm{mm}^{3}$. Four weeks after (July 12, 2005), his plasma viral load was 320 copies/mL, while his CD4+ cells count has increased to 196 cells $/ \mathrm{mm}^{3}$. Besides report of full adherence to ARV therapy, measures 3 and 5 months after initiation of viral load were 210 and 1400 copies/mL, respectively; he only became undetectable 9 months after and remained as such since then (36 months) (Figure 1). The patient's HLA type was Locus $\mathrm{A}^{\star} 23,24 \mathrm{~B}^{\star} 1503,35 \mathrm{Cw}^{\star} 02,04$.

\section{DISCUSSION}

The natural history of HIV infection is highly variable., ${ }^{2,9}$ However, most infected individuals remain free of symptoms for 6-10 years after initial infection, and a subset of infected individuals do not progress to AIDS after being infected for more than 25 years (so called "long-term non-progressors"). Differences in the speed of HIV-1 disease progression have been linked to several factors; most consistently to genetic factors, including chemokine polymorphisms and the expression of specific HLA class I or KIR alleles. ${ }^{10,11}$ On the other hand, there are rare individuals who progress to AIDS in a very short time after initial exposure to HIV. In MACS cohort a rate $<1 \%$ of rapid progression to AIDS within 12

Figure 1: Timeline

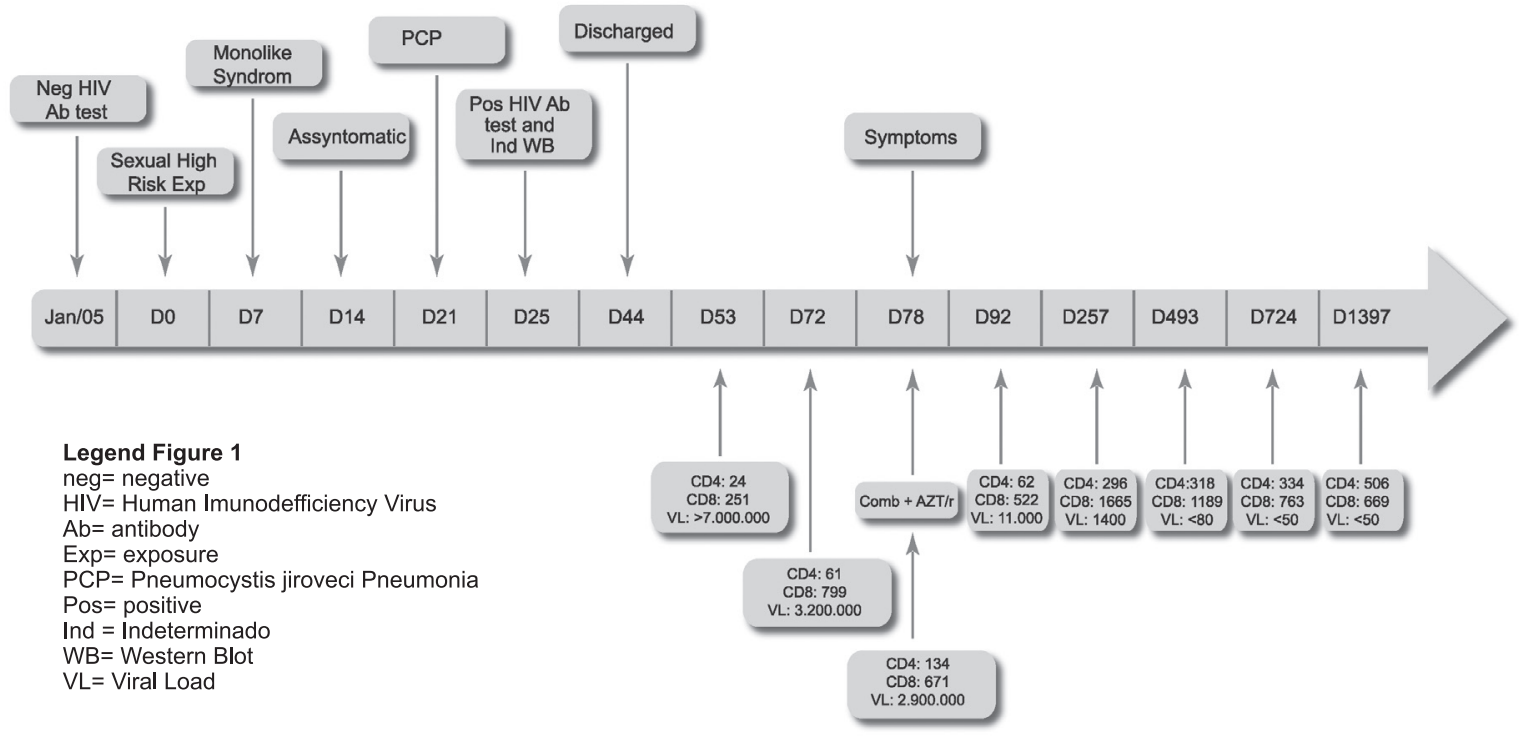


months of infection was reported with $0.007 \%$ of individuals reaching a CD4+ cell count less than 200 cells/ $\mathrm{mm}^{3}$ within 6 months of infection, and $0.045 \%$ within one year. ${ }^{12,13}$ The factors that are responsible for the rapid progression of disease in these individuals are not known.

Recently, a case of a man who developed AIDS, including the need for ARV therapy within 4-5 months after acute infection, was reported, and potential co-factors, such as life-style, use of drugs, or even an exceptionally virulent resistant strain of HIV have been discussed in this context. ${ }^{14}$ There are some cases of $P$. jiroveci in literature, but all recovered CD4 levels without ARV therapy within four months after symptoms. ${ }^{15}$ In the present case, the study subject did not report any drug use and he had stable HIV negative sex-partner. It was previously reported that HLA-B ${ }^{\star} 35, \mathrm{Cw}^{\star} 04$ and $\mathrm{A}^{\star} 68$ were associated with increased risk of fast progression to AIDS; ${ }^{16-19}$ of these, our patient has the first two antigens. In addition, the HIV-1 strain isolated was sensitive to all current antiretroviral drugs, and belonged to subtype $\mathrm{B}$, the most frequent viral subtype circulating in Bahia and associated with non-aggressive progression, ${ }^{20}$ however, the dual tropic viral profile was related to a increased risk of fast progression. ${ }^{14}$ Most importantly, this case emphasizes that physicians must be aware that life threatening opportunistic infections can occur during this early phase of infection. Acute HIV-1 infection can occasionally result in a rapid and dramatic loss of CD4+ T cells.

\section{REFERENCES}

1. Kahn JO, Walker BD. Acute human immunodeficiency virus type 1 infection. N Engl J Med 1989; 339(1):33-9.

2. Munoz A, Wang MC, Bass S et al. Acquired immunodeficiency syndrome (AIDS)-free time after human immunodeficiency virus type $1(\mathrm{HIV}-1)$ seroconversion in homosexual men. Am J Epidemiol 1989; 130:530-9.

3. Rutherford GW, Lifson AR, Hessol NA et al. Course of HIV-1 infection in a cohort of homosexual and bisexual men: an 11 year follow up study. Br Med J 1990; 301:1183-8.

4. Baccheti P, Moss AR. Incubation period of AIDS in San Francisco. Nature 1989; 16:251-3.

5. Stevenson M. HIV-1 pathogenesis. Nature Medicine 2003; 9:853-60.
6. Rodriguez B, Sethi AK, Cheruvu VK et al. Predictive value of plasma HIV RNA level on rate of CD4 T-cell decline in untreated HIV infection. JAMA 2006 Sep 27; 296(12):1498506.

7. Mellor JW, Rinaldo CR Jr, Gupto P et al. Prognosis in HIV-1 infection predicted by the quantity of virus in plasma. Science 1996; 272(5265):1167-70.

8. Harrigan R. Predicting response to CCR5 Antagonists. Oral Session, 16th Conference on Retroviruses and Opportunistic Infections, CROI 2009.

9. Lifson AR, Rutherford GW, Jaffe HW. The natural history of human immunodeficiency virus infection. J Infect Dis 1998; 158:1360-7.

10. Magierowska M, Theodorou I, Debré P et al. Combined genotypes of CCR5, CCR2, SDF1, and HLA genes on predict the long-term nonprogressor status in human immunodeficiency virus 1 infected individuals. Blood 1999; 93:936-41.

11. Flores-Villanueva PO, Yunis EJ, Delgado JC et al. Control of HIV-1 viremia and protection from AIDS are associated with HLA BW4 homozygosity. Proc Natl Acad Sci USA 2001; 98:5140-5.

12. Gange S. Data on natural history. Symposium on the Case of Rapidly Progressive Multi-drug Resistant HIV in New York City, February 10, 2005.

13. Phair J, Jacobson L, Detils R et al. acquired immunodefiency syndrome occurring within 5 years of infection with human immunodeficiency virus type-1: The Multicenter AIDS Cohort Study. JAIDS 1992; 5:490-6.

14. Markowitz M, Mohri $\mathrm{H}$, Mehandru S et al. Infection with multidrug resistant, dual-tropic HIV-1 and rapid progression to AIDS: a case report. Lancet 2005; 365:1031-8.

15. Vento S, Di Perri G, Garofano T et al. Pneumocystis carinii pneumonia during primary HIV-1 infection. Lancet 1993; 342:24-5.

16. Carrington M, Nelson GW, Martin MP et al. HLA and HIV-1: heterozygote advantage and $\mathrm{B}^{\star} 35-\mathrm{CW}^{\star} 04$ disadvantage. Science 1999; 283:1748-52.

17. Itescu S, Marthur-Wagh U, Skovron ML et al. HLA- B35 is associated with accelerated progression to AIDS. J Acquir Immune Defic Syndr 1992; 5:37-45.

18. Sahmoud T, Laurian Y, Gazengel C, Sultan Y, Gautreau C, Costagliola D. Progression to AIDS in French haemophiliacs: association with HLA-B35. AIDS 1993; 7:497-500.

19. Gao X, Nelson GW, Karacki P et al. Effect of a single amino acid change in MHC class I molecules on the rate of progression to AIDS. N Engl J Med 2001; 344:1688-75.

20. Taylor BS, Sobieszczyk ME, McCutchan FE et al. The challenge of HIV-1 subtype diversity. N Engl J Med 2008; 10:1590-602. 